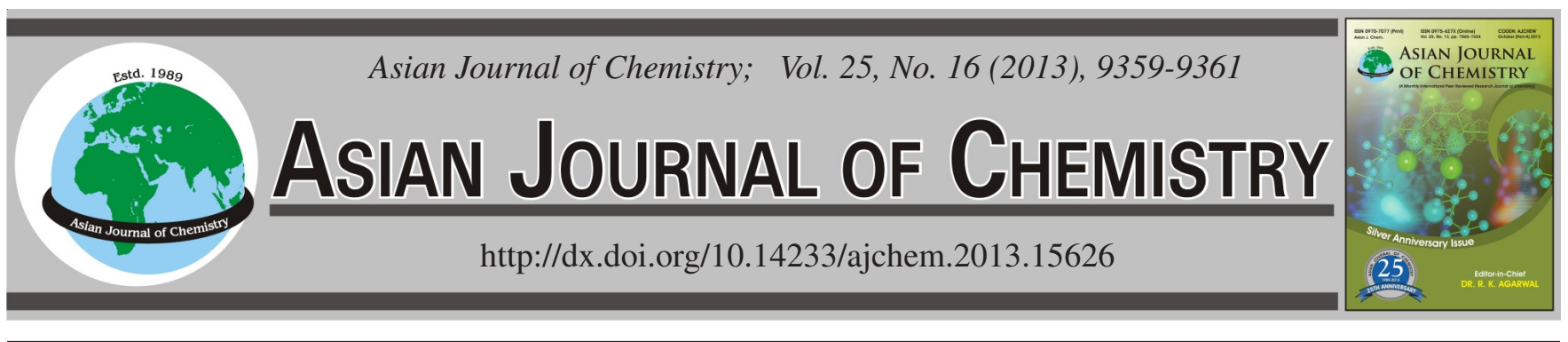

\title{
Synthesis and Structure Characterization of Copper(II) Complexes with 5,5'-Dihydroxy-2,2'-[ethylenedioxybis(nitrilomethylidyne)]diphenol
}

Yu-Hua Yang, Li-Sha Zhang, Gang Li*, Meng-Meng Zhao, Zheng-Kun Wang, Xin-Ying Zhang and JiaO-Long Meng School of Chemical and Biological Engineering, Lanzhou Jiaotong University, Lanzhou 730070, P.R. China

*Corresponding author: E-mail: li_gang78@126.com

(Received: 12 April 2013;

Accepted: 25 September 2013)

AJC-14178

A new tetradentate bis-oxime chelating ligand, 5,5'-dihydroxy-2,2'-[ethylenedioxybis(nitrilomethylidyne)]diphenol $\left(\mathrm{H}_{4} \mathrm{~L}\right)$ and its two $\mathrm{Cu}$ (II) complexes 1 and 2 have been synthesized by the reaction of $\mathrm{H}_{4} \mathrm{~L}$ with copper(II) acetate monohydrate and copper(II) picrate tetrahydrate, respectively. The complexes have been characterized by elemental analyses, IR spectra, UV-visible spectra, TG-DTA and molar conductances. The salen-type bisoxime chelating ligand is a good tetradentate $\mathrm{N}_{2} \mathrm{O}_{2}$-donating ligand and the likely formulae of the $\mathrm{Cu}(\mathrm{II})$ complexes may be suggested as $\left[\mathrm{Cu}\left(\mathrm{H}_{2} \mathrm{~L}\right)\right] \cdot \mathrm{CH}_{3} \mathrm{CH}_{2} \mathrm{OH} \cdot 2 \mathrm{H}_{2} \mathrm{O}(\mathbf{1})$ and $\left[\mathrm{Cu}_{2}\left(\mathrm{H}_{2} \mathrm{~L}\right)(\text { picrate })_{2}\right] \cdot \mathrm{H}_{2} \mathrm{O}(\mathbf{2})$.

Key Words: Cu(II) complex, Salen-type bisoxime compound, Synthesis, Characterization.

\section{INTRODUCTION}

In recent years, transition metal complexes bearing an $\mathrm{N}, \mathrm{N}$-disalicylideneethylenediamine (Salen) ligand or its analogues are extensively studied because these complexes are used as catalysts in various organic reactions ${ }^{1}$, non-linear optical materials ${ }^{2}$ and exhibit interesting magnetic properties ${ }^{3}$. The oxime-type ligands should be stable enough to resist the metathesis of the $\mathrm{C}=\mathrm{N}$ bonds ${ }^{4}$. Linear derivatives bearing two salicylaldoxime moieties at both ends have been reported. In this paper, a new Salen-type chelating ligand based on O-alkyloxime instead of the imine moiety, 5,5'-dihydroxy-2,2'[ethylenedioxybis(nitrilomethylidyne)]diphenol $\left(\mathrm{H}_{4} \mathrm{~L}\right)$ (Fig. 1) and the corresponding copper(II) complexes were synthesized and characterized.

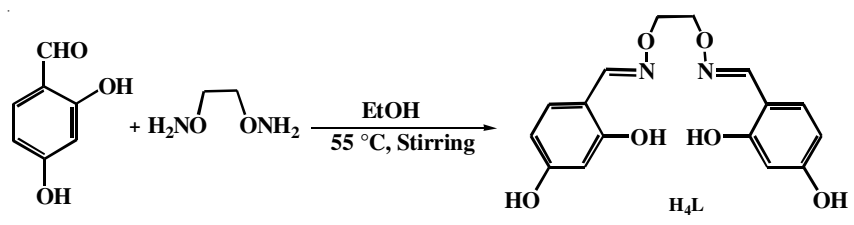

Fig. 1. Synthetic route to salen-type bisoxime compound

\section{EXPERIMENTAL}

2,4-Dihydroxybenzaldehyde ( $\geq 99.0 \%$ ) was purchased from Alfa Aesar and was used without further purification. 1,2-Bis(aminooxy)ethane was synthesized according to an analogous method reported earlier ${ }^{5-9}$. Elemental analysis for $\mathrm{Cu}$ was detected by an IRIS ER/S.WP-1 ICP atomic emission spectrometer. $\mathrm{C}, \mathrm{H}$ and $\mathrm{N}$ analyses were carried out with a GmbH VariuoEL V3.00 automatic elemental analyzer. FT-IR spectra were recorded on a VERTEX70 FT-IR spectrophotometer, with samples prepared as $\mathrm{KBr}\left(4000-400 \mathrm{~cm}^{-1}\right)$. UVVIS absorption spectra were recorded on a Shimadzu UV-2550 spectrometer. TG-DTA analyses were carried out at a heating rate of $5^{\circ} \mathrm{C} / \mathrm{min}$ on a ZRY-1P thermoanalyzer. Melting points were obtained by use of an $\mathrm{X} 4$ microscopic melting point apparatus made in Beijing Taike Instrument Limited Company and were uncorrected. Molar conductance value measurements were carried out on a model DDS-11D type conductivity bridge using $1.0 \times 10^{-3} \mathrm{~mol} \mathrm{dm}^{-3}$ solution in DMF at $25^{\circ} \mathrm{C}$.

Synthesis of ligand $\mathbf{H}_{\mathbf{4}} \mathbf{L}$ : A solution of 1,2-bis(aminooxy)ethane ( $92.5 \mathrm{mg}, 1.00 \mathrm{mmol})$ in ethanol $(8 \mathrm{~mL})$ was added to a solution of 2,4-dihydroxybenzaldehyde (290.1 mg, 2.10 $\mathrm{mmol})$ in ethanol $(8 \mathrm{~mL})$ and the mixture solution was heated to $55^{\circ} \mathrm{C}$ under stirring for $6 \mathrm{~h}$. After cooling to room temperature, the precipitate was filtered and washed successively with ethanol and ethanol $/ n$-hexane (1:4), respectively. The product was dried under reduced pressure and purified with recrystallization from ethanol to yield $277.6 \mathrm{mg}$ of pale-pink crystalline solid. Yield 83.6 \%. m.p. 219-220 ${ }^{\circ} \mathrm{C}$. ${ }^{1} \mathrm{H}$ NMR (400 MHz, $\left.\mathrm{CDCl}_{3}\right) \delta: 4.28(\mathrm{~s}, 4 \mathrm{H}), 6.29(\mathrm{~d}, J=7.6,1.4 \mathrm{~Hz}, 4 \mathrm{H}), 7.30$ (d, $J=8.0 \mathrm{~Hz}, 2 \mathrm{H}), 8.27$ (s, 2H), 9.80 (s, 2H), 9.94 (s, 2H).

Synthesis of $\mathrm{Cu}(\mathrm{II})$ complex 1: A solution of copper(II) acetate monohydrate $(20.1 \mathrm{mg}, 0.10 \mathrm{mmol})$ in ethanol $(3 \mathrm{~mL})$ was added dropwise to a solution of $\mathrm{H}_{4} \mathrm{~L}(33.2 \mathrm{mg}, 0.10 \mathrm{mmol})$ in ethanol $(3 \mathrm{~mL})$ at room temperature. The colour of the mixing solution turned to black and then continuing stirring 
for $10 \mathrm{~h}$ at room temperature. the resulting solid was filtered off, washed with ethanol/ether (1:4) and ether, respectively. The product was dried in vacuo and obtained $33.5 \mathrm{mg}$ of black solid. Yield $70.6 \%$.

Synthesis of $\mathbf{C u}($ II) complex 2: To an ethanol solution ( $5 \mathrm{~mL}$ ) of $\mathrm{H}_{4} \mathrm{~L}(33.2 \mathrm{mg}, 0.10 \mathrm{mmol})$ was added an ethanol solution $(5 \mathrm{~mL})$ of copper(II) picrate tetrahydrate $(59.5 \mathrm{mg}$, $0.10 \mathrm{mmol}$ ). After the mixture solution had been stirred at room temperature for $10 \mathrm{~h}$, the formed precipitate was separated by filtration and washed successively with ethanol/ether (1:4) and ether, respectively. The product was dried under reduced pressure to obtain $71.2 \mathrm{mg}$ of yellow solid. Yield $76.6 \%$.

\section{RESULTS AND DISCUSSION}

5,5'-Dihydroxy-2,2'-[ethylenedioxybis(nitrilomethylidyne)]diphenol $\left(\mathrm{H}_{4} \mathrm{~L}\right)$ and its two $\mathrm{Cu}(\mathrm{II})$ complexes $\mathbf{1}$ and $\mathbf{2}$ have been synthesized and the composition are confirmed by elemental analyses, IR, UV-visible spectra and TG-DTA analyses.

The colour, yields, melting points and elemental analytical, molar conductance results of the synthesized salamotype bisoxime compounds $\mathrm{H}_{4} \mathrm{~L}$ and its two $\mathrm{Cu}$ (II) complexes $\mathbf{1}$ and $\mathbf{2}$ are presented in Table-1.

The elemental analysis data of $\mathrm{H}_{4} \mathrm{~L}$ and its two $\mathrm{Cu}$ (II) complexes $\mathbf{1}$ and $\mathbf{2}$ are very close to the theoretical values, to prove the accuracy of analytical results. Copper(II) acetate monohydrate forms a 1:1 type (M:L) complex with the ligand $\mathrm{H}_{4} \mathrm{~L}$ which contains one ethanol and two water molecules in the complex 1 molecule, whereas the copper(II) picrate tetrahydrate forms a 2:1 type (M:L) complex in the complex 2 molecule which contains two picrate and one water molecules. The molar conductance values of complexes $\mathbf{1}$ and $\mathbf{2}$ in $1.0 \times$ $10^{-3} \mathrm{~mol} \mathrm{dm}^{-3} \mathrm{DMF}$ solutions are 7.81 and $8.87 \mathrm{~S} \mathrm{~cm}^{2} \mathrm{~mol}^{-1}$ at $21^{\circ} \mathrm{C}$, respectively, indicating that both are non-electrolytes ${ }^{10}$. Both $\mathrm{Cu}(\mathrm{II})$ complexes aren't easy to absorb moisture and have a fairly good stability in air. The ligand $\mathrm{H}_{4} \mathrm{~L}$ can be dissolved in most solvents. The complex $\mathbf{1}$ is soluble in strongly polar solvents such as DMF and DMSO, but insoluble in weakly polar and non-polar organic solvent; the complex $\mathbf{2}$ have a good solubility, not only soluble in strongly polar solvents such as DMF and DMSO but also soluble in methanol, ethanol, etc. weakly polar solvents, but insoluble in $n$-hexane, benzene and acetonitrile.

The most important FT-IR spectral data for $\mathrm{H}_{4} \mathrm{~L}$ and its corresponding $\mathrm{Cu}(\mathrm{II})$ complexes are given in Table-2. The characteristic $\mathrm{C}=\mathrm{N}$ stretching band of the free ligand $\mathrm{H}_{4} \mathrm{~L}$ appears at $1608 \mathrm{~cm}^{-1}$, while the $\mathrm{C}=\mathrm{N}$ bands of $\mathrm{Cu}$ (II) complexes 1 and 2 are observed at 1617 and $1610 \mathrm{~cm}^{-1}$, blue shift of 2-9 $\mathrm{cm}^{-1}$, respectively. The Ar-O stretching band occurs at 1246 $\mathrm{cm}^{-1}$ for $\mathrm{H}_{4} \mathrm{~L}$, whereas those at 1215 and $1217 \mathrm{~cm}^{-1}$ for complexes 1 and 2 , red shift of $29-31 \mathrm{~cm}^{-1}$, respectively. These shifts of $\mathrm{C}=\mathrm{N}$ and $\mathrm{Ar}-\mathrm{O}$ stretching frequencies indicate that the $\mathrm{Cu}-\mathrm{N}$ and $\mathrm{Cu}-\mathrm{O}$ bonds are formed between the $\mathrm{Cu}$ (II) ions and the oxime $\mathrm{N}$ and the phenolic $\mathrm{O}$ atoms of deprotonated $(\mathrm{L})^{2-}$ unit $^{8}$. Meanwhile, the $\mathrm{OH}$ out-of-plane bending vibration of the free HPic at $1148 \mathrm{~cm}^{-1}$ appears in the spectrum of complex 2 , indicating that the $\mathrm{H}$-atom of the $\mathrm{OH}$ group existed in complex $2^{11}$. The free HPic has $v_{a s}\left(-\mathrm{NO}_{2}\right)$ and $\mathrm{v}_{\mathrm{s}}\left(-\mathrm{NO}_{2}\right)$ at 1555 and $1342 \mathrm{~cm}^{-1}$, respectively, which split into two bands at $1577,1543,1372$ and $1332 \mathrm{~cm}^{-1}$. This indicates that some of the nitryl $\mathrm{O}$ atoms take part in coordination ${ }^{12,13}$. In addition, the infrared spectra of the complexes $\mathbf{1}$ and $\mathbf{2}$ show the expected absorptions due to the stretching and bending modes of water at 3226 and $1630 \mathrm{~cm}^{-1}$, respectively, indicating the presence of a water molecule ${ }^{8 f}$.

The absorption spectra data of $\mathrm{H}_{4} \mathrm{~L}$ and its corresponding $\mathrm{Cu}$ (II) complexes $\mathbf{1}$ and $\mathbf{2}$ (Table-3), in diluted DMF solution show that the spectra of complexes $\mathbf{1}$ and $\mathbf{2}$ are similar to each other, but are different from the spectrum of the ligand $\mathrm{H}_{4} \mathrm{~L}$. The UV-visible spectrum of the free ligand $\mathrm{H}_{4} \mathrm{~L}$ exhibits two absorption peaks at 276 and $311 \mathrm{~nm}$. The former absorption peak at $276 \mathrm{~nm}$ can be assigned to the $\pi-\pi^{*}$ transition of the benzene rings and the latter one at $311 \mathrm{~nm}$ can be attributed to the intra-ligand $\pi-\pi^{*}$ transition of the $\mathrm{C}=\mathrm{N}$ bonds ${ }^{14}$.

TABLE-1

COLOUR, YIELDS AND ANALYTICAL DATA OF $\mathrm{H}_{4}$ L AND ITS COPPER(II) COMPLEXES

\begin{tabular}{|c|c|c|c|c|c|c|c|c|}
\hline \multirow{2}{*}{ Compound } & \multirow{2}{*}{ m.f. (m.w.) } & \multirow{2}{*}{ Colour } & \multirow{2}{*}{$\begin{array}{l}\text { Yield } \\
(\%)\end{array}$} & \multicolumn{4}{|c|}{ Found (calcd.) (\%) } & \multirow{2}{*}{$\begin{array}{l}\text { Molar conductance } \\
\quad\left(\mathrm{S} \mathrm{cm}^{2} \mathrm{~mol}^{-1}\right)\end{array}$} \\
\hline & & & & $\mathrm{C}$ & $\mathrm{H}$ & $\mathrm{N}$ & $\mathrm{Cu}$ & \\
\hline $\mathrm{H}_{4} \mathrm{~L}$ & $\mathrm{C}_{10} \mathrm{H}_{10} \mathrm{~N}_{2} \mathrm{O}_{6}(332.1)$ & Pale-pink & 83.6 & $58.03(57.83)$ & $5.08(4.85)$ & $7.96(8.43)$ & - & - \\
\hline 1 & $\mathrm{C}_{18} \mathrm{H}_{24} \mathrm{CuN}_{2} \mathrm{O}_{9}(475.1)$ & Black & 70.6 & $45.24(45.42)$ & $4.89(5.08)$ & $6.02(5.89)$ & $13.56(13.35)$ & 7.81 \\
\hline 2 & $\mathrm{C}_{28} \mathrm{H}_{20} \mathrm{Cu}_{2} \mathrm{~N}_{8} \mathrm{O}_{21}$ (929.9) & Yellow & 76.6 & $36.25(36.10)$ & $2.11(2.16)$ & $11.88(12.02)$ & $13.4213 .64)$ & 8.87 \\
\hline
\end{tabular}

TABLE-2

MOST IMPORTANT FT-IR BANDS FOR $\mathrm{H}_{4}$ L AND ITS COPPER(II) COMPLEXES $\left(\mathrm{cm}^{-1}\right)$

\begin{tabular}{cccccc}
\hline Compound & $v(\mathrm{C}=\mathrm{N})$ & $v(\mathrm{Ar}-\mathrm{O})$ & $v(\mathrm{O}-\mathrm{H})$ & $\delta\left(\mathrm{H}_{2} \mathrm{O}\right)$ & $v(\mathrm{C}=\mathrm{C})$ benzene ring skeleton \\
\hline $\mathrm{H}_{4} \mathrm{~L}$ & 1631 & 1209 & 3356 & 1627 & $1517,1467,1430$ \\
$\mathbf{1}$ & 1617 & 1215 & 3226 & 1630 & $1543,1443,1341$ \\
$\mathbf{2}$ & 1610 & 1270 & 3371 & 1632 & $1610,1437,1340$ \\
\hline
\end{tabular}

TABLE-3

UV-VIS SPECTRAL DATA OF $\mathrm{H}_{4}$ L AND ITS COPPER(II) COMPLEXES

\begin{tabular}{|c|c|c|c|c|c|}
\hline \multirow{2}{*}{ Compound } & \multirow{2}{*}{$\mathrm{C}\left(\times 10^{-4} \mathrm{~mol} \mathrm{~L}^{-1}\right)$} & \multicolumn{2}{|c|}{ First band } & \multicolumn{2}{|c|}{ Second band } \\
\hline & & $\lambda_{\max 1}(\mathrm{~nm})$ & $\varepsilon_{1}\left(\times 10^{4} \mathrm{~L} \mathrm{~mol}^{-1} \mathrm{~cm}^{-1}\right)$ & $\lambda_{\max 2}(\mathrm{~nm})$ & $\varepsilon_{2}\left(\times 10^{4} \mathrm{~L} \mathrm{~mol}^{-1} \mathrm{~cm}^{-1}\right)$ \\
\hline $\mathrm{H}_{4} \mathrm{~L}$ & 1.00 & 276 & 2.54 & 311 & 2.09 \\
\hline 1 & 1.00 & 296 & 3.72 & 356 & 2.03 \\
\hline 2 & 1.00 & 299 & 2.78 & 372 & 4.71 \\
\hline
\end{tabular}


TABLE-4

THERMAL ANALYSIS DATA OF $\mathrm{H}_{4}$ L AND ITS COPPER(II) COMPLEXES

\begin{tabular}{|c|c|c|c|c|c|c|c|}
\hline \multirow{2}{*}{ Compound } & \multirow{2}{*}{$\begin{array}{c}\text { Endothermic } \\
\text { peak temp. }\left({ }^{\circ} \mathrm{C}\right)\end{array}$} & \multicolumn{2}{|c|}{ Weight loss rate $(\%)$} & \multirow{2}{*}{$\begin{array}{c}\text { Exothermic } \\
\text { peak temp. }\left({ }^{\circ} \mathrm{C}\right)\end{array}$} & \multicolumn{2}{|c|}{ Residual weight rate $(\%)$} & \multirow{2}{*}{$\begin{array}{c}\text { Final } \\
\text { product }\end{array}$} \\
\hline & & Found & Calcd. & & Found & Calcd. & \\
\hline $\mathrm{H}_{4} \mathrm{~L}$ & 220 & 25.1 & 24.8 & 241 & - & - & - \\
\hline 1 & 85,154 & $9.4,7.7$ & $9.7,7.6$ & 284,336 & 16.5 & 16.7 & $\mathrm{CuO}$ \\
\hline 2 & 128,206 & $2.1,49.1$ & $1.9,49.3$ & 278,342 & 16.9 & 17.1 & $\mathrm{CuO}$ \\
\hline
\end{tabular}

Compared with the absorption peak of the free ligand, a corresponding absorption peak at 296 and $299 \mathrm{~nm}$ is observed in complexes $\mathbf{1}$ and $\mathbf{2}$, respectively, which is hypsochromically shifted by $12-15 \mathrm{~nm}$, indicating the coordination of $\mathrm{Cu}$ (II) ions with deprotonated $\left(\mathrm{H}_{2} \mathrm{~L}\right)^{2-}$ unit $^{8}$. In addition, the new bands observed at 356 and $372 \mathrm{~nm}$ for complexes $\mathbf{1}$ and $\mathbf{2}$ are assigned to the $n-\pi^{*}$ charge transfer transition from the filled $p-\pi$ orbital of the bridging phenolic oxygen to the vacant $d$-orbital of the $\mathrm{Cu}$ (II) ions, which are characteristic of the transition metal complexes with $\mathrm{N}_{2} \mathrm{O}_{2}$ coordination spheres ${ }^{15}$.

Thermal properties: The experimental results show that the thermal behaviour of the free ligand $\mathrm{H}_{4} \mathrm{~L}$ is significantly different from the $\mathrm{Cu}$ (II) complexes. The free ligand $\mathrm{H}_{4} \mathrm{~L}$ has a small sharp endothermic peak at $220^{\circ} \mathrm{C}$ in DTA curve, with no weight loss in the TG curve, which is its melting point. On further heating, the free ligand $\mathrm{H}_{4} \mathrm{~L}$ has a exothermic peak at $241{ }^{\circ} \mathrm{C}$, with a weight loss in the TG curve and the ligand decompose completely by one step. Thermal analysis data of $\mathrm{H}_{4} \mathrm{~L}$ and its copper complexes are given in Table-4.

Compared to the free ligand $\mathrm{H}_{4} \mathrm{~L}$, the endothermic peaks of complex 1 appear at 85 and $154{ }^{\circ} \mathrm{C}$ in DTA curve and the TG curve shows that the weight loss corresponding to this temperature range is 9.4 and $7.7 \%$ that roughly coincides with the values of 9.7 and $7.6 \%$, respectively, calculated for the loss of one coordinated ethanol and two coordinated water molecules of complex $\mathbf{1}$, which is consistent with the results of infrared spectroscopy. The DTA curve of complex 2 shows two endothermic peaks at 128 and $206{ }^{\circ} \mathrm{C}$ with the weight losses of 2.1 and $49.1 \%$, respectively, which are agreement with the losses of one water $(1.93 \%)$ and two picric acid $(49.3 \%)$ molecules. On further heating, two exothermic peaks successively at 284 and $336^{\circ} \mathrm{C}$ for complex $1\left(278\right.$ and $342^{\circ} \mathrm{C}$ for complex 2 ) in the DTA curve and a continued weight loss occurs in the TG curve. Then, the second strong exothermic peak at $336{ }^{\circ} \mathrm{C}$ for complex 1 (at $342{ }^{\circ} \mathrm{C}$ for complex 2) accompanied with further decomposition of the complex and the final solid product is likely to $\mathrm{CuO}$ with a residual value of $16.5 \%$ (theoretical value, $16.7 \%$ ) for complex 1 and $16.9 \%$ (theoretical value, $17.1 \%$ ) for complex 2 when the temperature is above $800{ }^{\circ} \mathrm{C}$.

\section{REFERENCES}

1. T. Katsuki, Coord. Chem. Rev., 140, 189 (2009).

2. P.G. Lacroix, Eur. J. Inorg. Chem., 14, 339 (2001).

3. J.-P. Costes, F. Dahan and A. Dupuis, Inorg. Chem., 39, 165 (2000).

4. K. Koehler, W. Sandstrom and E.H. Cordes, J. Am. Chem. Soc., 86, 2413 (1964).

5. M. Maneiro, M.R. Bermejo, M. Fondo, A.M. González, J. Sanmartin, J.C. Garcia-Monteagudo, R.G. Pritchard and A.M. Tyryshkin, Polyhedron, 20, 711 (2001).

6. H.-B. Zhu, Z.-Y. Dai, W. Huang, K. Cui, Sh.-H. Gou and Ch.-J. Zhu, Polyhedron, 23, 1131 (2004).

7. S. Akine, T. Matsumoto, S. Sairenjia and T. Nabeshima, Supramol. Chem., 23, 106 (2011).

8. (a) W.K. Dong, X.N. He, H.B. Yan, Z.W. Lv, X. Chen, C.Y. Zhao and X.L. Tang, Polyhedron, 28, 1419 (2009); (b) W.K. Dong, Y.X. Sun, G.H. Liu, L. Li, X.Y. Dong and X.H. Gao, Z. Anorg. Allg. Chem., 638, 1370 (2012); (c) W.K. Dong, S.J. Xing, Y.X. Sun, L. Zhao, L.Q. Chai and X.H. Gao, J. Coord. Chem., 65, 1212 (2012); (d) W.K. Dong, Y.X. Sun, S.J. Xing, Y. Wang and X.H. Gao, Z. Naturforsch., 67b, 197 (2012); (e) W.K. Dong, Y.X. Sun, Y.P. Zhang, L. Li, X.N. He and X.L. Tang, Inorg. Chim. Acta, 362, 117 (2009); (f) W.K. Dong and J.G. Duan, J. Coord. Chem., 61, 781 (2008).

9. D.K. Aliakbar, A. Mehdi and T. Smail. Inorg. Chim. Acta, 362, 587 (2009).

10. W.J. Geary, Coord. Chem. Rev., 7, 81 (1971).

11. X.Q. Song, J.R. Zheng, W.S. Liu and Z.H. Ju, Spectrochim. Acta A, 69, 49 (2008).

12. S.X. Liu, W.S. Liu, M.Y. Tan and K.B. Yu, J. Coord. Chem., 10, 391 (1996).

13. X.Q. Song, W.S. Liu, W. Dou, Y.W. Wang, J.R. Zheng and Z.P. Zang, Eur. J. Inorg. Chem., 1901 (2008).

14. T. Ghosh, B. Mondal, T. Ghosh, M. Sutradhar, G. Mukherjee and M.G.B. Drew, Inorg. Chim. Acta, 360, 1753 (2007).

15. L. Gomes, E. Pereira and B. Castro, J. Chem. Soc. Dalton Trans., 1373 (2000). 